\title{
The Effect of PSE and Non-PSE Adductor and Semimembranosus Pig Muscles on the Occurrence of Destructured Zones in Cooked Hams
}

\author{
Martina Eliášová, ${ }^{1}$ Josef Kameník, ${ }^{2}$ Alena Saláková, ${ }^{2}$ Zdeněk Pavlík, ${ }^{3}$ \\ Matej Pospiech, ${ }^{1}$ and Bohuslava Tremlová ${ }^{1}$ \\ ${ }^{1}$ Department of Vegetable Foodstuffs Hygiene and Technology, Faculty of Veterinary Hygiene and Ecology, \\ University of Veterinary and Pharmaceutical Sciences Brno, Palackého Tř. 1946/1, 61242 Brno, Czech Republic \\ ${ }^{2}$ Department of Meat Hygiene and Technology, Faculty of Veterinary Hygiene and Ecology, \\ University of Veterinary and Pharmaceutical Sciences Brno, Palackého Tř. 1946/1, 612 42 Brno, Czech Republic \\ ${ }^{3}$ Experta Partner s.r.o., Dulánek 10a, 61500 Brno, Czech Republic \\ Correspondence should be addressed to Josef Kameník; kamenikj@vfu.cz
}

Received 10 May 2017; Revised 3 August 2017; Accepted 24 August 2017; Published 4 October 2017

Academic Editor: Anca Ioana Nicolau

Copyright ( 2017 Martina Eliášová et al. This is an open access article distributed under the Creative Commons Attribution License, which permits unrestricted use, distribution, and reproduction in any medium, provided the original work is properly cited.

\begin{abstract}
The aim of this study was to analyse pig muscles used in the production of cooked hams with a view to the occurrence of PSE-type defects and their potential effect on the frequency of destructured zones in finished products. One hundred and six samples of $m$. adductor (AD) and $m$. semimembranosus (SM) pig muscles were studied. The two kinds of muscle differed from each other in terms of their $\mathrm{pH}$ values and colour $\left(L^{*}\right.$ : lightness, $a^{*}:$ redness, and $b^{*}$ : yellowness); these differences between the two categories were statistically significant $(P<0.001)$. The AD muscles were divided into meat with PSE (pale, soft, and exudative) defects and non-PSE meat by sensory examination. A total of $44.3 \%$ of $\mathrm{AD}$ muscles showed PSE defects. Lightness $L^{*}$ fell within a range of 50.68-55.23 in non-PSE meat (AD) and was statistically significantly lower $(P<0.001)$ than in PSE meat $(56.25-58.78)$. Drip loss $(\mathrm{AD})$ was higher $(P<0.001)$ in PSE meat $(4.83-6.27 \%)$ than in non-PSE meat $(3.53-5.0 \%)$. Cooked hams prepared from pig muscles showed evident destructured zones when sliced, the number and overall area of which were not affected by the occurrence of PSE defects in the raw meat used.
\end{abstract}

\section{Introduction}

Cooked hams are popular meat products in Europe and throughout the world [1-3]. The basic raw meat used in the production of cooked hams is pork leg which is comprised of a number of anatomically different muscles.

PSE (pale, soft, and exudative) defects are most commonly encountered in pork meat [4]. PSE defects cause a serious economic problem in the production of cooked hams [5-7]. Efforts have been made for a number of years to reduce the occurrence of PSE meat and to find reliable indicators $(\mathrm{pH}$, colour, texture, electrical conductivity, etc.) that would make it possible to identify such defects before processing. Final products with improved properties that are acceptable to the consumer can be obtained by separating PSE meat from defect-free meat showing the standard parameters of fresh meat [4].

In the European Union, primarily in its eastern part, meat processors import pork from abroad. This has significant disadvantages, including great variability in the quality of the pork and the difficulties associated with checking quality at the slaughterhouse immediately after slaughter. The application of the routine analytical methods used for the classification of PSE meat defects is debatable when imported meat can be examined around 72 hours postmortem at the earliest, the principal reason being that the majority of parameters such as $\mathrm{pH}$, colour, and drip loss are determined within one and/or 24 hours postmortem [8-11].

Deviations in meat quality may appear in cooked hams in the form of destructured zones $[6,12-15]$ and have been 
a fundamental problem for meat processors in recent decades $[16,17]$. The occurrence of destructured zones differs according to various authors and between individual countries [12, $14,18]$. Destructured zones are described as "pale, soft, and exudative" zones inside cooked ham that are unsuitable for mechanical slicing after cooking in view of their impaired consistency [15].

Modern methods including image analysis are currently used for the evaluation of foodstuffs. The advantages of these methods are noninvasive acquisition of information from spatially complex samples [19-21] and this information can be obtained when analyses are based on a single photo [22]. Image analysis can substitute for many expensive and timeconsuming laboratory methods [23] and is often used to establish correlations between parameters obtained by image analysis and physicochemical methods [24].

Image analysis has been applied in many studies for the quality evaluation of meat and meat products [25-27]. Faucitano et al. [28] used it to determine the amount of fat in meat, while Nam et al. [10], Bañón et al. [8], and Warriss et al. [29] used it to detect PSE meat. Valous et al. [30] utilised image analysis as a quantitative descriptor in the evaluation of texture in cooked ham slices.

The aim of this study was to perform an analysis of $\mathrm{AD}$ and SM pig muscles (topside muscles) used in the production of cooked hams with a view to the occurrence of PSEtype defects and their potential effect on the frequency of destructured zones in cooked hams. Image analysis was used to examine cooked hams for the occurrence of destructured zones in the second part of the study. The correlation between the frequency of destructured zones in cooked hams and PSE defects in meat used in their preparation was then determined.

\section{Materials and Methods}

2.1. Meat Samples. Selected quality traits in $\mathrm{AD}$ and $\mathrm{SM}$ pig muscles from six foreign suppliers: $\mathrm{R}$ (BE), S (AT), T (DE), $\mathrm{U}(\mathrm{DE}), \mathrm{V}(\mathrm{DK})$, and $\mathrm{Z}(\mathrm{NL})$ were assessed 72 hours postmortem. The meat was tested using subjective and objective (instrumental) methods. Sensory tests were performed by three experienced evaluators who adjudged meat colour, water binding capacity, and texture. Pork Quality Standards [31] were used for the subjective evaluation. All evaluators had to agree on sample classification. The meat was divided into two groups, the first group showing signs of PSE (PSEinclined) and the second being non-PSE meat (standard, normal quality) on the basis of this sensory assessment. Evaluation was also performed using instrumental methods (colour in the CIEL ${ }^{*} a^{*} b^{*}$ system, texture using a WarnerBratzler test) and $\mathrm{pH}$ and drip loss values were measured. Twenty AD and 20 SM muscles from each supplier were tested, with the exception of supplier U, from which only 6 muscles were tested. A total of $106 \mathrm{AD}$ and $106 \mathrm{SM}$ muscles were tested. The values of $\mathrm{pH}$, colour $\left(L^{*}, a^{*}, b^{*}\right)$, drip loss, and texture by Warner-Bratzler were determined for $\mathrm{AD}$ muscle and the values of $\mathrm{pH}$ and colour $\left(L^{*}, a^{*}, b^{*}\right)$ for SM muscle.
2.2. Measurement of $\mathrm{pH}$ and Meat Colour. Measurement of $\mathrm{pH}$ value and meat colour was performed in the cutting room at a production plant. The $\mathrm{pH}$ value was measured using a WTW pH 340i (WTW GmbH, Weilheim, Germany) pH meter with a Double Pore needle probe (Hamilton Bonaduz AG, Bonaduz, Switzerland). The instrument was calibrated to $\mathrm{pH} 4$ and $\mathrm{pH} 7$ before measurements were taken. The $\mathrm{pH}$ value was determined at two different places in the core of each muscle (AD, SM). Colour was instrumentally measured by the CIEL ${ }^{*} a^{*} b^{*}$ system using a Minolta CM2600d spectrophotometer (Konica Minolta, Osaka, Japan) on the cut of raw meat samples. The instrument was calibrated on a white reference plate. Each sample was measured in triplicate with an aperture opening of $8 \mathrm{~mm}, 10^{\circ}$ viewing angle, and D65 illuminant. $L^{*}$, lightness, $a^{*}$, redness, and $b^{*}$, yellowness, were calculated using available software (Spectra Magic 3.61).

2.3. Drip Loss and Texture Determination Using a WarnerBratzler Test. The drip loss of AD samples was determined by Honikel [32]. Samples $(100 \mathrm{~g} \pm 0.01 \mathrm{~g})$ were placed in polyethylene bags and stored flat for 24 hours in a refrigerator at approximately $5 \pm 2{ }^{\circ} \mathrm{C}$ and weighed again. Percent drip loss was calculated using the following formula:

$$
\text { Drip loss }=\frac{m_{1}-m_{2}}{m_{1}} \times 100[\%] \text {, }
$$

where $m_{1}$ is weight before refrigerated storage and $m_{2}$ is weight after refrigerated storage.

The objective measurement of texture was performed using a Warner-Bratzler test (W-B) on an INSTRON 5544 system (Instron Corporation, Norwood, USA). Meat texture was evaluated in raw samples [33] of $1 \mathrm{~cm} \times 1 \mathrm{~cm} \times 2.5 \mathrm{~cm}$ in size to assess the maximum shear force $(\mathrm{N})$ of the meat. The specimen was sheared perpendicularly to the muscle fibres at a constant speed of $50 \mathrm{~mm} \cdot \mathrm{s}^{-1}$ and then pushed through the slot. Six determinations were performed for each raw sample.

2.4. Production of Cooked Hams. Two groups of cooked hams (PSE CH and STANDARD $\mathrm{CH}$ ) were produced from the meat of three selected suppliers (U, V, and Z). The meat was injected (Metalquimia, Girona, Spain) with brine at a quantity of $13 \%$ of the meat by volume. The composition of the brine was water and Naturham (Natura Food Additives, Havlíckův Brod, Czech Republic) containing phosphates, dextrose, sodium ascorbate, and carrageenans. The proportion of nitrite curing salt $\left(0.5 \% \mathrm{NaNO}_{2}\right)$ was $2.0 \%$ in the finished product. The injected meat was tumbled 20 minutes at $4^{\circ} \mathrm{C}$, under a vacuum in a VSM-CC tumbler (GLASS $\mathrm{GmbH} \&$ Co. KG, Paderborn, Germany), rested for 12 hours at $2^{\circ} \mathrm{C}$, filled into technological packing $(\mathrm{PA} / \mathrm{EVOH} / \mathrm{PA} / \mathrm{PE}$ bags with oxygen transmission rate $<5 \mathrm{~cm}^{3} / \mathrm{m}^{2} / 24 \mathrm{~h} / 23^{\circ} \mathrm{C}$ ) by hand, vacuum packed (S 223, VAC-STAR, Pardubice, Czech Republic), put into the mould (internal length $220 \mathrm{~mm}$; internal diameter $150 \mathrm{~mm}$ ) and cooked (core temperature $70^{\circ} \mathrm{C} / 10$ minutes) in a Convotherm (OSP, Eglfing, Germany), and cooled to $2^{\circ} \mathrm{C}$. The weight of each ham was $3 \mathrm{~kg}$. A total of 


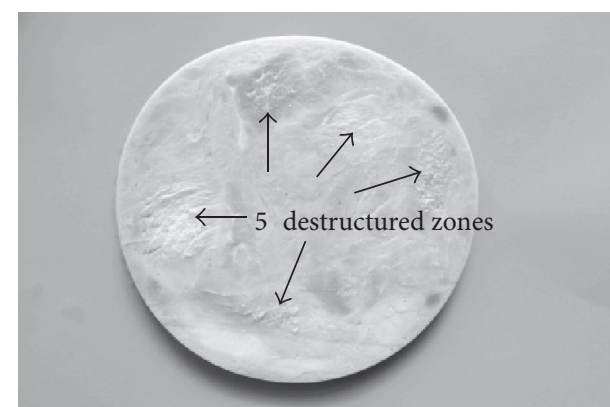

(a)

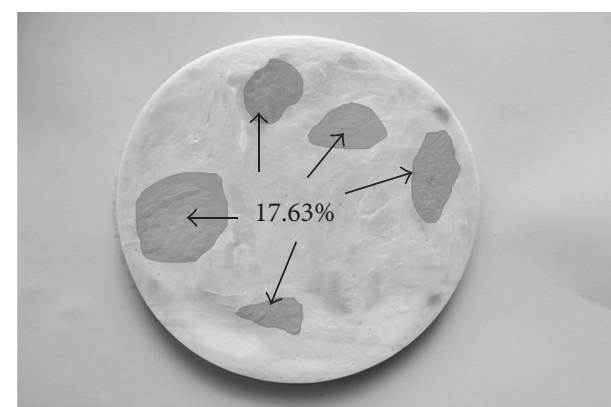

(b)

FIGURE 1: The cut surface of a cooked ham with determination of the number of destructured zones (a) and the total area of these zones (b).

nine cooked hams were prepared from meat classified as PSE and nine cooked hams made from standard meat (non-PSE).

2.5. Image Analysis of Cooked Hams. Samples of cooked hams were cut into slices $1.5 \mathrm{~cm}$ thick $\times 15.0 \mathrm{~cm}$ in size on which the number and extent of destructured zones were evaluated. The occurrence of destructured zones was evaluated in 20 slices of STANDARD $\mathrm{CH}$ and 20 slices of PSE $\mathrm{CH}$ using image analysis under daylight conditions (overcast, 6000-6200 K). The camera was mounted above the sample with a focal distance of $25 \mathrm{~cm}$. To ensure uniform conditions, a calibrated $30 \mathrm{~cm}$ ruler was used (KINEX, CSN251125, Czech Republic). Photographs of the slices of cooked ham were taken with a Canon EOS 450 D camera (Canon, Tokyo, Japan) in daylight, contrast blue background, and standard camera settings (MANU, ISO 100, shutter speed 1/100, aperture F 6.3, RAW format). The photographs were subsequently analysed in the program Adaptive Contrast Control Structure and Object Analyser version 6.1, Sofo-ACC (Brno, Czech Republic). In the first step, the number of destructured zones was calculated (Figure 1(a)). The total area of the cooked ham slice on the photograph $(100 \%)$ was then determined automatically from the contrast in colour of the background and the cooked ham slices. Destructured zones were delineated (Figure 1(b)) and their total area on each slice was calculated in \% of the total sample area using ACC tools.

2.6. Statistical Evaluation. The results obtained were processed statistically in the program Statistica CZ 7 (Statsoft, Prague, Czech Republic). Differences in muscles (m. adductor and $m$. semimembranosus) from different suppliers (R, S, T, U, $\mathrm{V}$, and $\mathrm{Z}$ ) and between PSE meat and non-PSE meat in colour $\left(L^{*}, a^{*}\right.$, and $\left.b^{*}\right), \mathrm{pH}$, drip loss, and texture were compared using one-way ANOVA with a post hoc Tukey HSD test $(P<0.05,0.01$, and 0.001$)$. The parameters were subjected to a correlation analysis (Pearson's coefficient and Goodman and Kruskal's gamma coefficient for the appearance of PSE) in order to determine potential statistical relationships.

The data related to the occurrence of destructured zones was processed statistically using an independent two-sample $t$-test $(P<0.05)$. Differences in the number and area of destructured zones between cooked hams made from meat identified as non-PSE (STANDARD CH) and meat identified as PSE (PSE CH) were compared.

\section{Results and Discussion}

3.1. PSE and Non-PSE AD and SM Pig Muscles. The physicochemical traits are given in Table 1 . A pH value within a range of 5.43-5.59 in AD and 5.52-5.80 in SM $(P<0.001)$ was measured in the meat from all suppliers. Our results differ from those published by Hugenschmidt et al. [15] who measured a higher $\mathrm{pH}$ in $\mathrm{AD}(5.49-6.16)$ than in $\mathrm{SM}$ (5.45-5.83) 72 hours postmortem. Bucko et al. [34] reported $\mathrm{pH}$ values 24 hours postmortem $\left(\mathrm{pH}_{24}\right)$ of 5.72 in $\mathrm{AD}$ and 5.73 in $\mathrm{SM}$, with no significant difference between the individual muscles. Weschenfelder et al. [35] measured a $\mathrm{pH}_{24}$ of 6.07 in $\mathrm{AD}$ muscle and 5.69 in SM muscle.

Similar to $\mathrm{pH}$ values, the values of lightness $L^{*}(P<$ $0.001), a^{*}(P<0.001)$, and $b^{*}(P<0.001)$ also differed between AD and SM (Table 1). Lightness $L^{*}$ values measured in SM in this study were similar to those reported by Scheier et al. [36] who measured an average $L^{*}$ value of 48.1 after 24 hours postmortem in SM. Similar values of $a^{*}$ were recorded in $\mathrm{SM}$ (5.99-8.04) as in $\mathrm{AD}$ (3.85-8.73). Texture differed in $\mathrm{AD}$ from individual suppliers. The greatest value of shear force was measured in samples from supplier S $(103.27 \mathrm{~N})$, the lowest from supplier Z (63.36 N). Minimal differences between suppliers were observed in relation to the values of drip loss in AD muscle $(P>0.05)$.

Table 2 shows the values of colour $\left(L^{*}, a^{*}\right.$, and $\left.b^{*}\right), \mathrm{pH}$ value, texture according to the Warner-Bratzler test, and drip loss in AD muscles classified as non-PSE and PSE, indicating that PSE defects were identified in 47 samples (44.3\%). Some pieces of pork meat were extremely light in colour, even pink, and looked rather like fish muscle. A texture of a spongy nature was found when the piece of muscle was squeezed. Our results indicate an occurrence considerably higher than that given in the literature which states an occurrence of PSE of $2-30 \%[11,37]$.

Clear differences in the values measured for non-PSE and PSE meat can be seen in Table 2 for all suppliers. Lightness $L^{*}$ fell within a range of 50.68-55.23 for non-PSE meat and was statistically significantly lower $(P<0.001)$ than for meat with PSE defects which ranged from 56.25 to 58.78 . Values of $\mathrm{pH}$ differ between PSE (5.40-5.47) and non-PSE (5.45-5.71) meat $(P<0.001)$. The drip loss supports the sensory identification of PSE meat. Drip loss was higher in PSE meat which showed 
TABLe 1: Physical properties of $m$. adductor (AD) and $m$. semimembranosus (SM) (mean \pm SD). The colour of $m$. adductor (AD) and $m$. semimembranosus (SM) was measured by the CIELAB system, the $\mathrm{pH}$ value was detected 72 hours p.m. by $\mathrm{pH}$ meter with a Double Pore needle probe, the Warner-Bratzler test (W-B) was performed on an INSTRON 5544 instrument, and drip loss was evaluated using polyethylene bag and filter paper.

\begin{tabular}{|c|c|c|c|c|c|c|c|}
\hline Supplier & Muscle & $L^{*}$ & $a^{*}$ & $b^{*}$ & $\mathrm{pH}$ & W-B (N) & Drip loss (\%) \\
\hline \multirow{2}{*}{$\begin{array}{l}\mathrm{R} \\
(n=20)\end{array}$} & $\mathrm{AD}$ & $56.12 \pm 2.78$ & $8.37^{\mathrm{B}} \pm 2.49$ & $15.19^{B} \pm 2.71$ & $5.44^{\mathrm{A}} \pm 0.08$ & $94.35^{\mathrm{A}} \pm 15.48$ & $4.71 \pm 1.17$ \\
\hline & SM & $46.57^{\mathrm{a}, \mathrm{b}, \mathrm{c}} \pm 2.49$ & $7.83^{\mathrm{a}} \pm 1.56$ & $10.40 \pm 1.28$ & $5.52^{\mathrm{a}} \pm 0.12$ & - & - \\
\hline \multirow{2}{*}{$\begin{array}{l}S \\
(n=20)\end{array}$} & $\mathrm{AD}$ & $55.81 \pm 2.56$ & $6.24^{\mathrm{A}, \mathrm{B}} \pm 2.99$ & $13.47^{\mathrm{B}} \pm 2.82$ & $5.43^{\mathrm{A}, \mathrm{B}} \pm 0.06$ & $103.27^{\mathrm{A}} \pm 9.97$ & $5.12 \pm 1.65$ \\
\hline & SM & $47.56^{\mathrm{a}, \mathrm{b}, \mathrm{c}} \pm 3.59$ & $6.85^{\mathrm{a}, \mathrm{b}} \pm 1.68$ & $10.12^{\mathrm{a}} \pm 2.06$ & $5.56^{\mathrm{a}, \mathrm{b}} \pm 0.12$ & - & - \\
\hline \multirow{2}{*}{$\begin{array}{l}\mathrm{T} \\
(n=20)\end{array}$} & $\mathrm{AD}$ & $57.18 \pm 1.83$ & $5.46^{\mathrm{A}} \pm 3.14$ & $13.81^{B} \pm 2.59$ & $5.46^{\mathrm{A}, \mathrm{B}} \pm 0.11$ & $67.70^{B} \pm 9.61$ & $5.07 \pm 1.42$ \\
\hline & SM & $48.53^{\mathrm{a}, \mathrm{b}, \mathrm{c}} \pm 3.02$ & $5.72^{\mathrm{b}} \pm 2.51$ & $10.14 \pm 2.33$ & $5.57^{\mathrm{a}, \mathrm{b}} \pm 0.19$ & - & - \\
\hline \multirow{2}{*}{$\begin{array}{l}\mathrm{U} \\
(n=6)\end{array}$} & $\mathrm{AD}$ & $54.03 \pm 3.52$ & $5.33^{\mathrm{A}} \pm 1.44$ & $12.31^{\mathrm{A}} \pm 1.75$ & $5.59^{\mathrm{B}} \pm 0.17$ & $86.25^{\mathrm{A}} \pm 8.52$ & $4.81 \pm 1.34$ \\
\hline & SM & $42.91^{\mathrm{a}} \pm 2.15$ & $6.75^{\mathrm{a}, \mathrm{b}} \pm 0.90$ & $8.63 \pm 0.90$ & $5.80^{\mathrm{b}} \pm 0.24$ & - & - \\
\hline \multirow{2}{*}{$\begin{array}{l}\mathrm{V} \\
(n=20)\end{array}$} & $\mathrm{AD}$ & $55.01 \pm 2.97$ & $4.63^{\mathrm{A}} \pm 2.29$ & $12.78^{\mathrm{A}} \pm 2.08$ & $5.49^{\mathrm{A}, \mathrm{B}} \pm 0.10$ & $98.08^{A} \pm 12.85$ & $5.27 \pm 1.58$ \\
\hline & SM & $43.83^{\mathrm{a}} \pm 2.91$ & $6.92^{\mathrm{a}, \mathrm{b}} \pm 1.38$ & $8.83^{\mathrm{b}} \pm 0.90$ & $5.64^{\mathrm{a}, \mathrm{b}, \mathrm{c}} \pm 0.20$ & - & - \\
\hline \multirow{2}{*}{$\begin{array}{l}Z \\
(n=20)\end{array}$} & $\mathrm{AD}$ & $56.29 \pm 2.94$ & $4.03^{\mathrm{A}} \pm 2.01$ & $12.25^{\mathrm{A}} \pm 1.71$ & $5.46^{\mathrm{A}} \pm 0.09$ & $63.36^{\mathrm{B}} \pm 13.89$ & $4.78 \pm 0.75$ \\
\hline & SM & $46.24^{\mathrm{a}, \mathrm{b}, \mathrm{c}} \pm 2.83$ & $6.46^{\mathrm{a}, \mathrm{b}} \pm 1.87$ & $9.70 \pm 1.18$ & $5.56^{\mathrm{a}, \mathrm{c}} \pm 0.18$ & - & - \\
\hline
\end{tabular}

$\overline{\mathrm{A}, \mathrm{B}}$ Different letters in the same column show statistically significant differences between individual suppliers $(P<0.05)$ for AD muscles. ${ }^{\mathrm{a}, \mathrm{b}, \mathrm{c}} \mathrm{Different}$ letters in the same column show statistically significant differences between individual suppliers $(P<0.05)$ for SM muscles. $L^{*}$ : lightness, $a^{*}$ : redness, $b^{*}$ : yellowness, W-B: Warner-Bratzler test-maximum shear force, AD: $m$. adductor, and SM: m. semimembranosus.

TABLE 2: Physical properties of $m$. adductor muscle identified as PSE and non-PSE (mean \pm SD). The colour of $m$. adductor (AD) was measured by the CIELAB system, the $\mathrm{pH}$ value was detected by a $\mathrm{pH}$ meter with a Double Pore needle probe, the Warner-Bratzler test (W-B) was performed on an INSTRON 5544 instrument, and drip loss was evaluated using a polyethylene bag and filter paper.

\begin{tabular}{|c|c|c|c|c|c|c|c|c|}
\hline Supplier & $\begin{array}{c}\text { PSE/ } \\
\text { non-PSE }\end{array}$ & $n$ & $L^{*}$ & $a^{*}$ & $b^{*}$ & $\mathrm{pH}$ & $\mathrm{W}-\mathrm{B}(\mathrm{N})$ & Drip loss (\%) \\
\hline \multirow{2}{*}{$\mathrm{R}$} & Non-PSE & 10 & $54.85^{\mathrm{A}} \pm 2.80$ & $8.01 \pm 2.72$ & $14.34 \pm 2.90$ & $5.45 \pm 0.09$ & $90.74 \pm 18.07$ & $4.59 \pm 1.27$ \\
\hline & PSE & 10 & $57.40^{\mathrm{B}} \pm 2.10$ & $8.73 \pm 2.18$ & $16.04 \pm 2.19$ & $5.42 \pm 0.08$ & $97.95 \pm 11.26$ & $4.83 \pm 1.06$ \\
\hline \multirow{2}{*}{ S } & Non-PSE & 11 & $54.47^{\mathrm{A}} \pm 2.45$ & $5.08 \pm 2.58$ & $12.14^{\mathrm{A}} \pm 2.32$ & $5.45 \pm 0.06$ & $101.02 \pm 9.96$ & $4.31^{\mathrm{A}} \pm 1.10$ \\
\hline & PSE & 9 & $57.46^{\mathrm{B}} \pm 1.50$ & $7.65 \pm 2.86$ & $15.09^{B} \pm 2.53$ & $5.40 \pm 0.04$ & $105.77 \pm 9.37$ & $6.10^{\mathrm{B}} \pm 1.68$ \\
\hline \multirow{2}{*}{$\mathrm{T}$} & Non-PSE & 11 & $56.68 \pm 2.10$ & $5.87 \pm 2.88$ & $13.96 \pm 2.83$ & $5.49 \pm 0.13$ & $67.79 \pm 10.81$ & $5.01 \pm 1.67$ \\
\hline & PSE & 9 & $57.80 \pm 1.17$ & $4.96 \pm 3.36$ & $13.61 \pm 2.25$ & $5.43 \pm 0.06$ & $67.58 \pm 7.89$ & $5.13 \pm 1.04$ \\
\hline \multirow{2}{*}{$\mathrm{U}$} & Non-PSE & 3 & $50.68^{\mathrm{A}} \pm 1.38$ & $4.37 \pm 1.14$ & $10.72 \pm 0.69$ & $5.71 \pm 0.17$ & $92.75 \pm 4.15$ & $3.53^{\mathrm{A}} \pm 0.41$ \\
\hline & PSE & 3 & $57.39^{\mathrm{B}} \pm 0.59$ & $6.29 \pm 1.00$ & $13.90 \pm 0.77$ & $5.47 \pm 0.04$ & $79.75 \pm 6.60$ & $6.09^{B} \pm 0.36$ \\
\hline \multirow{2}{*}{$\mathrm{V}$} & Non-PSE & 10 & $53.76 \pm 3.25$ & $3.85 \pm 2.05$ & $11.95 \pm 1.98$ & $5.55 \pm 0.09$ & $95.27 \pm 13.32$ & $4.26^{\mathrm{A}} \pm 1.26$ \\
\hline & PSE & 10 & $56.25 \pm 1.99$ & $5.41 \pm 2.25$ & $13.60 \pm 1.84$ & $5.42 \pm 0.04$ & $100.90 \pm 11.71$ & $6.27^{\mathrm{B}} \pm 1.16$ \\
\hline \multirow{2}{*}{ Z } & Non-PSE & 14 & $55.23^{\mathrm{A}} \pm 2.70$ & $4.10 \pm 1.70$ & $11.89 \pm 1.53$ & $5.48 \pm 0.10$ & $66.21 \pm 14.28$ & $4.70 \pm 0.67$ \\
\hline & PSE & 6 & $58.78^{\mathrm{B}} \pm 2.13$ & $3.87 \pm 2.71$ & $13.11 \pm 1.92$ & $5.42 \pm 0.06$ & $56.72 \pm 11.66$ & $4.97 \pm 0.93$ \\
\hline
\end{tabular}

$L^{*}$ : lightness, $a^{*}$ : redness, $b^{*}$ : yellowness, and W-B: Warner-Bratzler test-maximum shear force. ${ }^{\mathrm{A}, \mathrm{B}}$ Different letters in the same suppliers show statistically significant differences between non-PSE and PSE $(P<0.05)$.

a range of $4.83-6.27 \%$ than in non-PSE meat, with a range of 3.53-5.01\% $(P<0.001)$ for all suppliers.

The values of $L^{*}, a^{*}$, and $b^{*}$ and $\mathrm{pH}$ in $\mathrm{SM}$ are given in Table 3. The values of lightness $L^{*}$ in SM fall within a range of 44.00-49.38 in PSE meat and 41.82-47.84 in non-PSE meat $(P<0.001)$.

The results of the measurements taken by instrumental and physical methods correlate statistically significantly with the subjective classification of AD muscles into the PSE group (Table 4). A significant negative correlation between the values of $L^{*}(r=-0.449, P<0.01), b^{*}(r=-0.321, P<0.01)$, and drip loss $(r=-0.371, P<0.01)$ and a positive correlation with the $\mathrm{pH}$ value $(r=0.355, P<0.01)$ were recorded in PSE meat from AD. A significant positive correlation between PSE and lightness $L^{*}(r=0.345, P<0.01)$ and $b^{*}(r=0.202$, $P<0.05)$ and a negative correlation between PSE and $\mathrm{pH}$ $(r=-0.352, P<0.01)$ were recorded in SM.

Meat is most often classified as PSE by drip loss and the values of lightness $L^{*}$ and $\mathrm{pH}$, though various authors state differing threshold values. Identification of PSE defects is most commonly determined in $\mathrm{m}$. longissimus $[4,11,38,39]$. There are not so many studies in the literature concerning the 
TABLE 3: Physical properties of $m$. semimembranosus muscle identified as PSE and non-PSE (means \pm SD). The colour of $m$. semimembranosus $(S M)$ was measured by the CIELAB system; the $\mathrm{pH}$ value was detected by a $\mathrm{pH}$ meter with a Double Pore needle probe.

\begin{tabular}{lcccccc}
\hline Supplier & PSE/non-PSE & $n$ & $L^{*}$ & $a^{*}$ & $b^{*}$ \\
\hline R & Non-PSE & 10 & $45.53 \pm 2.31$ & $8.04 \pm 1.58$ & $10.00 \pm 1.28$ & $5.54 \pm 0.14$ \\
& PSE & 10 & $47.61 \pm 2.21$ & $8.04 \pm 1.58$ & $10.80 \pm 1.14$ & $5.50 \pm 0.09$ \\
S & Non-PSE & 11 & $46.39 \pm 3.49$ & $6.76 \pm 1.42$ & $9.78 \pm 1.76$ & $5.59 \pm 0.13$ \\
& PSE & 9 & $48.87 \pm 3.24$ & $6.95 \pm 1.93$ & $10.49 \pm 2.30$ & $5.53 \pm 0.09$ \\
T & Non-PSE & 11 & $47.84 \pm 2.26$ & $6.15 \pm 2.59$ & $10.07 \pm 2.60$ & $5.60 \pm 0.18$ \\
& PSE & 9 & $49.38 \pm 3.57$ & $5.18 \pm 2.30$ & $10.23 \pm 1.94$ & $5.53 \pm 0.18$ \\
U & Non-PSE & 3 & $41.82 \pm 2.07$ & $6.24 \pm 1.00$ & $8.45 \pm 1.13$ & $6.00^{\mathrm{a}} \pm 0.13$ \\
& PSE & 3 & $44.00 \pm 1.61$ & $7.27 \pm 0.31$ & $8.81 \pm 0.54$ & $5.60^{\mathrm{b}} \pm 0.13$ \\
V & Non-PSE & 10 & $42.17^{\mathrm{a}} \pm 2.13$ & $6.46 \pm 1.25$ & $8.20^{\mathrm{a}} \pm 0.67$ & $5.79^{\mathrm{a}} \pm 0.17$ \\
& PSE & 10 & $45.50^{\mathrm{b}} \pm 2.62$ & $7.39 \pm 1.35$ & $9.46^{\mathrm{b}} \pm 0.61$ & $5.50^{\mathrm{b}} \pm 0.11$ \\
$\mathrm{Z}$ & Non-PSE & 14 & $45.20^{\mathrm{a}} \pm 2.72$ & $6.66 \pm 2.10$ & $9.45 \pm 1.23$ & $5.61 \pm 0.19$ \\
& PSE & 6 & $48.68^{\mathrm{b}} \pm 1.50$ & $5.99 \pm 1.31$ & $10.26 \pm 0.94$ & $5.46 \pm 0.10$ \\
\hline
\end{tabular}

$L^{*}$ : lightness, $a^{*}$ : redness, and $b^{*}$ : yellowness. ${ }^{\text {a,b }}$ Different letters for the same suppliers show statistically significant differences between non-PSE and PSE $(P<0.05)$.

TABLE 4: Correlation coefficients and levels of significance in PSE and physical parameters. The parameters were subjected to a correlation analysis (Pearson's coefficient) in order to determine potential statistical relationships between PSE and colour, pH, Warner-Bratzler shear force, and drip loss in $m$. adductor (AD) and m. semimembranosus (SM).

\begin{tabular}{|c|c|c|c|c|c|c|c|c|c|c|}
\hline & \multicolumn{6}{|c|}{ M. adductor $(n=106)$} & \multicolumn{4}{|c|}{ M. semimembranosus $(n=106)$} \\
\hline & $L^{*}$ & $a^{*}$ & $b^{*}$ & $\mathrm{pH}$ & $\mathrm{W}-\mathrm{B}$ & Drip loss & $L^{*}$ & $a^{*}$ & $b^{*}$ & $\mathrm{pH}$ \\
\hline$\overline{a^{*}}$ & $0.284^{* *}$ & & & & & & 0.050 & & & \\
\hline$b^{*}$ & $0.597^{* * *}$ & $0.893^{* * *}$ & & & & & $0.733^{* * *}$ & $0.582^{* * *}$ & & \\
\hline $\mathrm{pH}$ & $-0.447^{* * *}$ & $-0.270^{* *}$ & $-0.331^{* * *}$ & & & & $-0.591^{* * *}$ & $-0.364^{* * *}$ & $-0.510^{* * *}$ & \\
\hline $\mathrm{W}-\mathrm{B}$ & -0.162 & $0.229^{*}$ & 0.098 & 0.096 & & & - & - & - & - \\
\hline Drip loss & $0.389^{* * *}$ & $0.365^{* * *}$ & $0.442^{* * *}$ & $-0.437^{* * *}$ & 0.027 & & - & - & - & - \\
\hline PSE & $-0.449^{* * *}$ & -0.190 & $-0.321^{* * *}$ & $0.355^{* * *}$ & -0.116 & $-0.371^{* * *}$ & $0.345^{* * *}$ & -0.005 & $0.202^{*}$ & $-0.352^{* * *}$ \\
\hline
\end{tabular}

${ }^{* * *} P<0.001,{ }^{* *} P<0.01$, and ${ }^{*} P<0.05 ; L^{*}$ : lightness, $a^{*}$ : redness, $b^{*}$ : yellowness, W-B: Warner-Bratzler test-maximum shear force, and PSE: the appearance of PSE meat.

detection of PSE in SM and AD muscles as there are regarding detection in m. longissimus. Schilling et al. [40], for example, classify PSE in AD and SM by a value of lightness $L^{*}$ higher than 53 and a pH beneath 5.5. This author measured average values of $L^{*} 57.6$ and $\mathrm{pH} 5.36$ for PSE and $L^{*} 45.8$ and $\mathrm{pH}$ 5.99 for non-PSE in AD and SM. Warriss et al. [29] measured values of lightness $L^{*}$ of 46.6 for $\mathrm{AD}$ muscle identified as PSE and 44.6 for non-PSE. Bañón et al. [8] state values of $L^{*}$ 49.2/pH 5.7 for PSE and $L^{*} 49.4 / \mathrm{pH} 5.6$ for non-PSE in SM, with the differences between PSE and standard meat being minimal. In this study, lightness $L^{*}$ attains values $<50$, as in the study by Bañón et al. [8], and there were differences here between PSE and non-PSE for both lightness $L^{*}(P<0.001)$ and $\mathrm{pH}(P<0.001)$.

3.2. Destructured Zones in Cooked Hams. The results relating to the number and area of destructured zones in cooked hams are given in Table 5. The largest occurrence of destructured zones in STANDARD $\mathrm{CH}$ made from non-PSE meat was found in samples from supplier V (25.81\%). The lowest occurrence was recorded in suppliers $\mathrm{U}(15.48 \%)$ and $\mathrm{Z}$ $(18.73 \%)$. The average occurrence of destructured zones attained similar values in the second group of cooked hams, that is, PSE CH The largest occurrence of destructured zones was recorded, similarly as in the case of STANDARD $\mathrm{CH}$, in supplier $\mathrm{V}(25.73 \%)$. A statistically significantly $(P<$ 0.01 ) lower occurrence of destructured zones was recorded in suppliers U (12\%) and Z (10.62\%) in comparison with supplier V. When STANDARD CH were compared with PSE CH, no statistically significant difference $(P>0.05)$ was found in the occurrence of destructured zones between STANDARD $\mathrm{CH}$ and PSE CH made from pork from all three suppliers (U, $\mathrm{V}$, and $\mathrm{Z}$ ). The total average area (regardless of supplier) of destructured zones was $18.87 \%$ in slices of STANDARD CH and $15.09 \%$ in PSE CH $(P>0.05)$. The number of destructured zones does not always correlate with the total area of the destructured zones on the slice examined. The largest number of destructured zones was recorded in supplier $\mathrm{Z}$ in both groups of cooked hams - the number of destructured zones per slice was 4.2 for STANDARD $\mathrm{CH}$ and 3 for PSE $\mathrm{CH}$ - while their area was $18.73 \%$ and $10.62 \%$, respectively. Fewer destructured zones were recorded in supplier $\mathrm{V}$ than in supplier $\mathrm{Z}-$ an average of 1.8 destructured zones per slice in STANDARD CH and 3 in PSE CH - while the area they covered was the highest in supplier V (25.73\%). The average number of destructured zones in STANDARD CH and PSE 
TABLE 5: The number and area of destructured zones (DZ) in hams (means \pm S.D.). The occurrence of destructured zones was evaluated in 20 slices of STANDARD CH and 20 slices of PSE CH with the use of image analysis. The area covered by destructured zones was indicated in $\%$ on each slice and their total area on the slice.

\begin{tabular}{|c|c|c|c|c|c|}
\hline \multirow{2}{*}{ Supplier } & \multirow{2}{*}{$n$ (number of slices) } & \multicolumn{2}{|c|}{ Area of DZ (\%) } & \multicolumn{2}{|c|}{ Number of DZ } \\
\hline & & STANDARD CH & PSE CH & STANDARD CH & PSE CH \\
\hline $\bar{U}$ & 10 & $15.48 \pm 7.34$ & $12.00 \pm 9.20$ & $2.50 \pm 0.85$ & $2.50 \pm 0.85$ \\
\hline $\mathrm{V}$ & 5 & $25.81 \pm 8.90$ & $25.73 \pm 5.00$ & $1.80 \pm 0.45^{*}$ & $3.00 \pm 0.71^{*}$ \\
\hline Z & 5 & $18.73 \pm 6.45$ & $10.62 \pm 4.49$ & $4.20 \pm 0.84$ & $3.00 \pm 1.41$ \\
\hline Total & 20 & $18.87 \pm 8.45$ & $15.09 \pm 9.31$ & $2.75 \pm 1.16$ & $2.75 \pm 0.97$ \\
\hline
\end{tabular}

DZ: destructured zones; STANDARD CH: cooked ham made of non-PSE meat; PSE CH: cooked ham made of PSE meat; ${ }^{*} P<0.05$.

$\mathrm{CH}$ from supplier $\mathrm{U}$ was the same at 2.5, with the area they covered being $15.48 \%$ (STANDARD $\mathrm{CH}$ ) and $12.00 \%$ (PSE $\mathrm{CH})$. When the number of destructured zones was compared in both groups of cooked hams, no statistically significant difference was found between the individual suppliers, with the exception of supplier $\mathrm{V}(P<0.05)$, as in the case of the area of destructured zones.

Laville et al. [13] stated that destructured zones are observed most commonly in $\mathrm{SM}, \mathrm{AD}$, and biceps femoris muscles, while Hugenschmidt et al. [15] indicated that AD is the muscle most susceptible to the occurrence of such defects. They also stated that such defects inside the muscle cannot be seen during the visual inspection of fresh meat which may be the reason for the occurrence of destructured zones in cooked hams made from PSE meat. The classification of meat into non-PSE and PSE was based on sensory analysis. Signs of PSE were not observed on the surface of pieces of meat identified as non-PSE, though the areas inside the muscle may have been affected by changes to meat proteins that may have appeared as a destructured zone in the final product. Defects to pork meat need not be merely PSE-type defects. Altmann et al. [41] investigated 20,364 pig sides at slaughterhouses in Germany and found an occurrence of PSE defects of between 1.2 and $8.8 \%$, though only $48.7 \%$ of the pig carcasses showed meat of good quality.

Structural defects in cooked hams often correlate with lower yields, problems with slicing, and higher water loss [16, 42]. The occurrence of destructured zones is reported differently in different European countries and by different authors. Balac et al. [12], for example, stated a 20-50\% occurrence of destructured zones. Franck et al. [42] reported around $20 \%$ destructured zones in cooked hams. Hugenschmidt et al. [14] conducted research in seven meat-processing plants in Switzerland. Destructured zones appeared in 7-8\% of slices of cooked ham resulting in considerable economic losses [14]. Neyrinck et al. [43] assessed 55 cooked hams following slicing, of which $79.9 \%$ were visually assessed as being of normal quality, with the presence of destructured zones being found in $29.1 \%$ of samples. Hugenschmidt et al. [15] stated that a reduced $\mathrm{pH}$ and the temperature immediately following slaughter may be identified in the raw muscle as an important predictor of the occurrence of destructured zones in cooked hams. The temperature immediately after slaughter, which may reach as much as $41^{\circ} \mathrm{C}$, contributes directly to the development of defects in ham by means of denatured proteins.
The authors of the study believe that mechanical stress during the tumbling process acts on muscle fibres altered by the effect of biochemical processes in the early stages postmortem. These factors taken together lead to the formation of the destructured zones evident on slices of cooked hams. The extent to which these changes result from biochemical processes in the muscle fibres and the extent to which the technology itself is responsible for these changes should be the subject of further studies.

\section{Conclusion}

The AD and SM pig muscles differed from one another with regard to traits such as $\mathrm{pH}$ value and meat colour $\left(L^{*} a^{*} b^{*}\right)$. These differences were statistically significant $(P<0.001)$ and possible to determine even 72 hours postmortem. Subjective assessment was backed up by measurement of selected meat parameters, and statistically significant differences $(P<$ 0.001 ) were found between the two groups of meat (PSE and non-PSE) in terms of $\mathrm{pH}$ value, lightness $L^{*}$, and drip loss. The number and area of destructured zones in slices of cooked hams are not related to the occurrence of PSEtype defects. The number and area of destructured zones did not differ between the groups of PSE cooked hams and STANDARD cooked hams. It is likely that factors other than PSE meat deviations also play a part in defects to cooked hams described as destructured zones. Determination of the precise cause of these defects requires further investigation, including investigation into the technology of cooked ham production.

\section{Additional Points}

Practical Applications. The number and area of destructured zones in slices of cooked hams are not related to the occurrence of PSE-type defects in raw pork topside muscles. It is likely that factors other than PSE meat deviations also play a part in defects to cooked hams described as destructured zones. Determination of the precise cause of these defects requires further investigation, including investigation into the technology of cooked ham production. Highlights. Samples of $m$. adductor (AD) and m. semimembranosus (SM) pig muscles were studied. A total of $44.3 \%$ of AD muscles showed PSE defects. Two groups of cooked hams were prepared from selected pig muscles. The cooked hams prepared showed evident destructured zones when sliced. The number and overall area of these zones were not affected by PSE defects. 


\section{Conflicts of Interest}

The authors declare that they have no conflicts of interest.

\section{Acknowledgments}

This work was supported by Institutional Research at the University of Veterinary and Pharmaceutical Sciences Brno, Faculty of Veterinary Hygiene and Ecology, and the company of MP Krásno a.s.

\section{References}

[1] J. Kameník, A. Saláková, Z. Pavlík et al., "Qualität der tschechischen Kochschinken," Fleischwirtschaft, vol. 93, no. 10, pp. 125130, 2013.

[2] H. Paelinck and S. Szczepaniak, "New strategies for the preservation of cooked ham," Polish Journal of Food and Nutrition Sciences, vol. 14, pp. 37-40, 2005.

[3] P. Talens, L. Mora, N. Morsy, D. F. Barbin, G. ElMasry, and D. Sun, "Prediction of water and protein contents and quality classification of Spanish cooked ham using NIR hyperspectral imaging," Journal of Food Engineering, vol. 117, no. 3, pp. 272280, 2013.

[4] T. Lesiów and Y. L. Xiong, "A simple, reliable and reproductive method to obtain experimental pale, soft and exudative (PSE) pork," Meat Science, vol. 93, no. 3, pp. 489-494, 2013.

[5] E. Laville, M. Franck, M. Sidibé et al., "Anatomical study of lesions in destructured ham," Sciences des Aliments, vol. 23, no. 1, pp. 70-74, 2003.

[6] D. J. O’Neill, P. B. Lynch, D. J. Troy, D. J. Buckley, and J. P. Kerry, "Effects of PSE on the quality of cooked hams," Meat Science, vol. 64, no. 2, pp. 113-118, 2003.

[7] V. Van de Perre, A. Ceustermans, J. Leyten, and R. Geers, "The prevalence of PSE characteristics in pork and cooked ham-Effects of season and lairage time," Meat Science, vol. 86, no. 2, pp. 391-397, 2010.

[8] S. Bañón, M. Gil, M. Granados, and M. Garrido, "The effect of using PSE meat in the manufacture of dry-cured ham," Zeitschrift fur Lebensmitteluntersuchung und -Forschung A, vol. 206, no. 2, pp. 88-93, 1998.

[9] T. L. Scheffler and D. E. Gerrard, "Mechanisms controlling pork quality development: The biochemistry controlling postmortem energy metabolism," Meat Science, vol. 77, no. 1, pp. 716, 2007.

[10] Y. J. Nam, Y. M. Choi, S. H. Lee et al., "Sensory evaluations of porcine longissimus dorsi muscle: Relationships with postmortem meat quality traits and muscle fiber characteristics," Meat Science, vol. 83, no. 4, pp. 731-736, 2009.

[11] J. Mlynek, I. Imrich, W. Kapelański, and E. Mlyneková, "Effect of transport, rest period and temperature on pork quality from different countries," Journal of Central European Agriculture, vol. 14, no. 2, pp. 751-757, 2013.

[12] D. Balac, C. Bazin, and Y. Le Treut, "Research of the factors able to influence the appearance of the syndrome of structureless hams," Polish Journal of Food And Nutrition Sciences, vol. 48, pp. 45-52, 1998.

[13] E. Laville, T. Sayd, V. Santé-Lhoutellier et al., "Characterisation of PSE zones in semimembranosus pig muscle," Meat Science, vol. 70, no. 1, pp. 167-172, 2005.
[14] G. Hugenschmidt, R. Hadorn, M. Suter, and C. Scheeder, "Wenk Anteil und Schweregrad destrukturierter Zonen in Kochschinken," Fleischwirtschaft, vol. 87, pp. 100-103, 2007.

[15] G. Hugenschmidt, R. Hadorn, M. R. L. Scheeder, P. Silacci, D. Scherrer, and C. Wenk, "The effects of early post-mortem $\mathrm{pH}$ and ultimate $\mathrm{pH}$ on level and amount of destructured zones in cooked cured hams," Meat Science, vol. 85, no. 4, pp. 632-639, 2010.

[16] G. Hugenschmidt, R. Hadorn, D. Guggisberg et al., "Chemische und physikalische Charakterisierung von Destruk-turierungen in Kochschinken," Fleischwirtschaft, vol. 89, pp. 86-91, 2009.

[17] I. F. Gorlov, E. I. Pershina, and S. L. Tikhonov, "Identification and prevention of the formation of meat with pse and DFD properties and quality assurance for meat products from feedstocks exhibiting an anomalous autolysis behavior," Foods and Raw Materials, vol. 1, no. 2, pp. 15-21, 2013.

[18] B. Minvielle, Y. Houix, and B. Lebret, "Viandes déstructurées. Facteurs de risque. Caractérisation colorimétrique, biochimique et histologique," Techni PORC, vol. 24, pp. 21-28, 2001.

[19] C. R. Butson and D. J. King, "Lacunarity analysis to determine optimum extents for sample-based spatial information extraction from high-resolution forest imagery," International Journal of Remote Sensing, vol. 27, no. 1, pp. 105-120, 2006.

[20] J. Chmiela, D. Słota, and J. Szala, "Analysis of emptiness (lacunarity) as a measure of the degree of space filling and of the internal structure of a set," Materials Characterization, vol. 56, no. 4-5, pp. 421-428, 2006.

[21] P. Dong, "Lacunarity analysis of raster datasets and 1D, 2D, and 3D point patterns," Computers and Geosciences, vol. 35, no. 10, pp. 2100-2110, 2009.

[22] M. G. O’Sullivan, D. V. Byrne, H. Martens, L. H. Gidskehaug, H. J. Andersen, and M. Martens, "Evaluation of pork colour: Prediction of visual sensory quality of meat from instrumental and computer vision methods of colour analysis," Meat Science, vol. 65, no. 2, pp. 909-918, 2003.

[23] K. L. Yam and S. E. Papadakis, "A simple digital imaging method for measuring and analyzing color of food surfaces," Journal of Food Engineering, vol. 61, no. 1, pp. 137-142, 2004.

[24] C. Zheng, D.-W. Sun, and L. Zheng, "Recent developments and applications of image features for food quality evaluation and inspection-a review," Trends in Food Science and Technology, vol. 17, no. 12, pp. 642-655, 2006.

[25] C. J. Du and D. W. Sun, "Recent developments in the applications of image processing techniques for food quality evaluation," Trends in Food Science \& Technology, vol. 15, no. 5, pp. 230-249, 2004.

[26] K. Dasiewicz, M. Slowinski, M. Walasek, A. Cegielka, M. Słowiński, and A. Cegiełka, "The use of colour measurements for determining the quality of meat from young cattle and culled cows," Animal Science Proceeding, vol. 1, pp. 33-34, 2007.

[27] P. Jackman, D.-W. Sun, and P. Allen, "Automatic segmentation of beef longissimus dorsi muscle and marbling by an adaptable algorithm," Meat Science, vol. 83, no. 2, pp. 187-194, 2009.

[28] L. Faucitano, P. Huff, F. Teuscher, C. Gariepy, and J. Wegner, "Application of computer image analysis to measure pork marbling characteristics," Meat Science, vol. 69, no. 3, pp. 537543, 2005.

[29] P. D. Warriss, S. N. Brown, and P. Paściak, "The colour of the adductor muscle as a predictor of pork quality in the loin," Meat Science, vol. 73, no. 4, pp. 565-569, 2006. 
[30] N. A. Valous, F. Mendoza, D.-W. Sun, and P. Allen, "Colour calibration of a laboratory computer vision system for quality evaluation of pre-sliced hams," Meat Science, vol. 81, no. 1, pp. 132-141, 2009.

[31] NPPC, Pork Quality Standards, National Pork Producers Council, Des Moines, Iowa, USA, 1999.

[32] K. O. Honikel, "Reference methods for the assessment of physical characteristics of meat," Meat Science, vol. 49, no. 4, pp. 447-457, 1998.

[33] F. Ruiz De Huidobro, E. Miguel, B. Blázquez, and E. Onega, "A comparison between two methods (Warner-Bratzler and texture profile analysis) for testing either raw meat or cooked meat," Meat Science, vol. 69, no. 3, pp. 527-536, 2005.

[34] O. Bucko, J. Petr, K. Vavri et al., "Chemical composition and quality characteristics of pork in selected muscles," in Book of Abstracts of the 63rd Annual Meeting of the European Federation of Animal Science, p. 217, European Federation of Animal Science, Bratislava, Slovakia, 2012.

[35] A. V. Weschenfelder, L. Saucier, X. Maldague, L. M. Rocha, A. L. Schaefer, and L. Faucitano, "Use of infrared ocular thermography to assess physiological conditions of pigs prior to slaughter and predict pork quality variation," Meat Science, vol. 95, no. 3, pp. 616-620, 2013.

[36] R. Scheier, A. Bauer, and H. Schmidt, "Early postmortem prediction of meat quality traits of porcine semimembranosus muscles using a portable raman system," Food and Bioprocess Technology, vol. 7, no. 9, pp. 2732-2741, 2014.

[37] J. E. Cannon, J. B. Morgan, F. K. McKeith et al., "Pork chain quality audit survey: Quantification of pork quality characteristics," Journal of Muscle Foods, vol. 7, no. 1, pp. 29-44, 1996.

[38] S. Kazemi, M. O. Ngadi, and C. Gariépy, "Protein denaturation in pork longissimus muscle of different quality groups," Food and Bioprocess Technology, vol. 4, no. 1, pp. 102-106, 2011.

[39] T. E. Lawrence, M. F. Spire, M. E. Dikeman, M. C. Hunt, S. B. Hogge, and B. W. James, "Utilizing infrared thermography to predict pork quality," in Report of Progress, B. Goodband, M. Tokach, and S. Dritz, Eds., pp. 131-134, Kansas State University Swine Day, 2001.

[40] M. W. Schilling, N. G. Marriott, J. C. Acton, C. AndersonCook, C. Z. Alvarado, and H. Wang, "Utilization of response surface modeling to evaluate the effects of non-meat adjuncts and combinations of PSE and RFN pork on water holding capacity and cooked color in the production of boneless cured pork," Meat Science, vol. 66, no. 2, pp. 371-381, 2004.

[41] M. Altmann, U. Kirchheim, L. Schöberlein, M. Wähner, M. Wicke, and K. Fischer, "PSE-Status bei marktkonformen Schweinen," Fleischwirtschaft, vol. 85, no. 7, pp. 101-104, 2005.

[42] M. Franck, G. Monin, P. Figwer, M. T. Poirel, and C. Legault, "Strukturloses Fleisch-ein ernsthaftes Problem: Problematik bei der industriellen Herstellung von Kochschinken," Fleischwirtschaft, vol. 82, pp. 97-100, 2002.

[43] E. Neyrinck, D. Telleir, S. Lescouhier et al., "Use of light based methods as prediction tool for the quality of fresh pork for cooked hams production," in Proceedings of the 59th International Congress of Meat Science and Technology, Izmir, Turkey, 2013. 

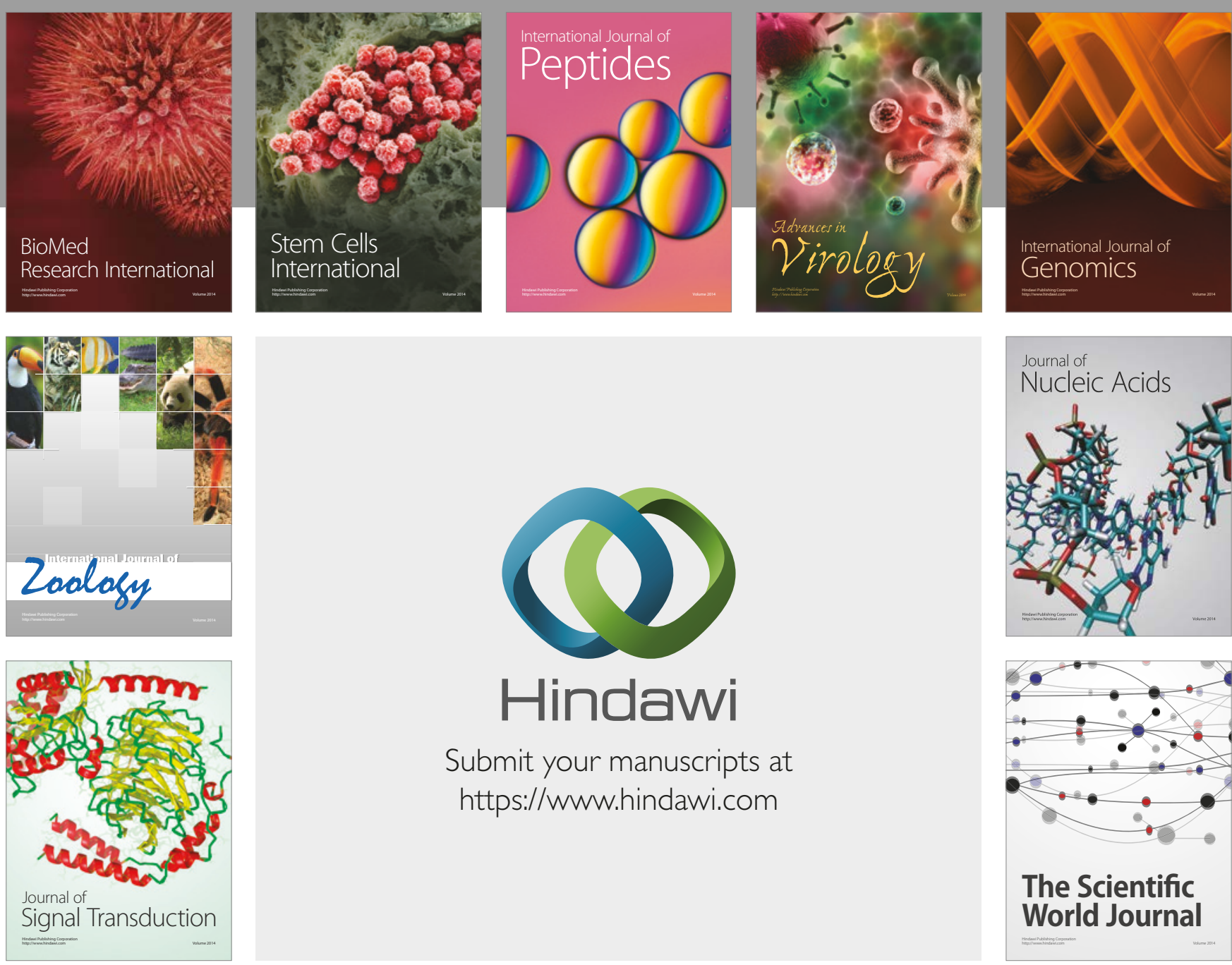

Submit your manuscripts at

https://www.hindawi.com
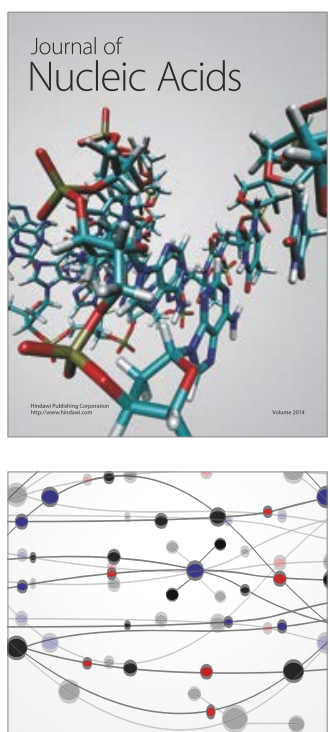

The Scientific World Journal

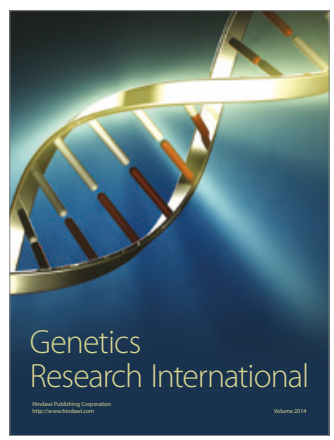

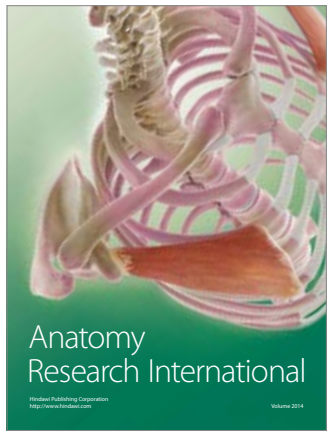

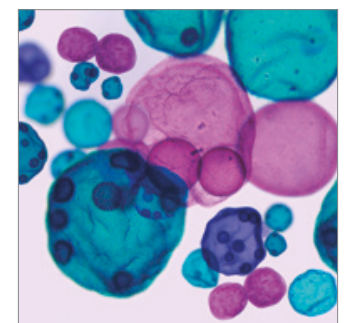

International Journal of Microbiology
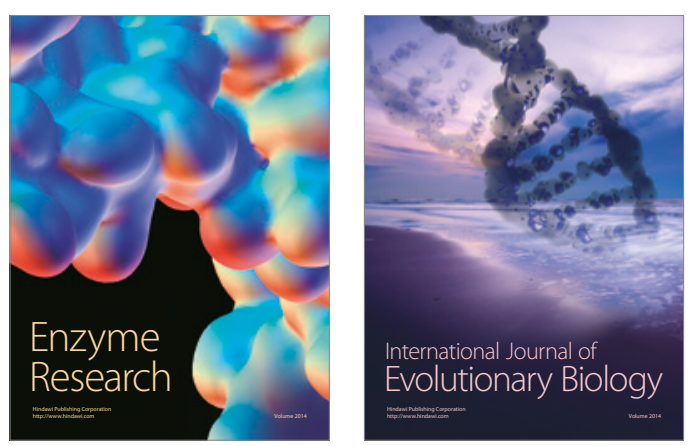
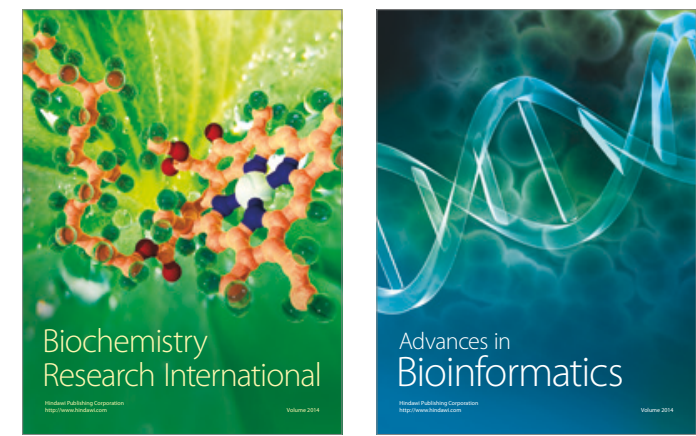

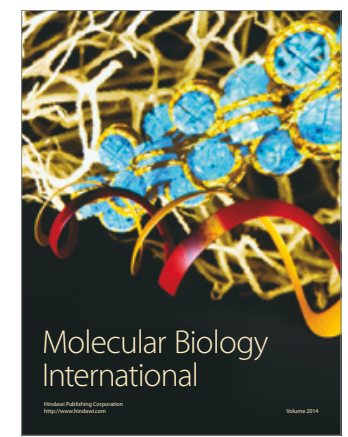

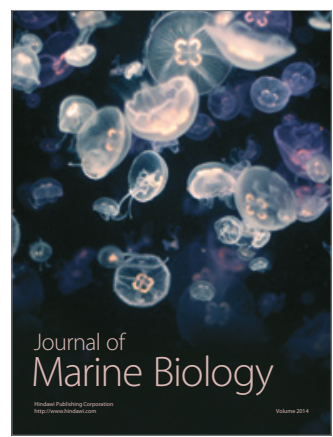

